\title{
FATIGUE CRACK GROWTH RETARDATION INCONEL 600
}

\author{
T. K. BROG, $\dagger$ J. W. JONES $\ddagger$ and G. S. WAS $\$$ \\ The University of Michigan, Ann Arbor, MI 48109, U.S.A.
}

\begin{abstract}
The effect of single-cycle overloads on the subsequent fatigue crack growth behavior of Inconel 600 is studied. Overloads ranging from 10 to $50 \%$ are applied to a sample undergoing baseline fatigue crack growth at constant $\Delta K$. In all cases, the crack growth rate increases slightly immediately after the overload and then decreases rapidly to a minimum value before later returning to the pre-overload value. The plastic zone size, affected crack length and the crack growth increment at minimum crack growth rate, $a^{\prime}$, are measured for each overload.

The affected crack length is considerably larger than the overload plastic zone size for overloads greater than $20 \%$. Consequently, although the minimum crack growth rate occurs within the plane stress overload plastic zone, the effect of the overload extends well beyond the overload region.

Within the overload plastic zone, contact occurs between the crack faces due to the excessive deformation produced during the overload cycle. The size of the contact region agrees very well with the overload plastic zone size. Beyond the overload region, $\Delta K_{\text {eff }}$ remains less than the applied $\Delta K$ for some time due to the wedge action of the plastically deformed overload region, delaying recovery of the pre-overload crack growth rate. The crack growth rate recovers only after the crack grows out of the region of influence of the wedge.
\end{abstract}

\section{INTRODUCTION}

IT IS NOw well established that the rate of fatigue crack growth may be significantly reduced by the application of single or multiple overload cycles. The resultant crack growth retardation is an important phenomenon which must be understood or at least quantified if accurate fatigue life prediction models for variable amplitude loading conditions are to be devloped.

Fatigue crack growth retardation has been attributed to: (1) physical crack closure[1,2], (2) residual compressive stresses associated with the overload plastic zone [3,4] or (3) crack tip geometry changes[5]. These phenomena, acting singly or in combination are believed to affect the crack tip stress intensity range and thus alter the fatigue crack propagation rate through a modification of the well-known Paris Law for fatigue crack growth:

$$
\mathrm{d} a / \mathrm{d} N=C\left(\Delta K_{\mathrm{eff}}\right)^{n}
$$

where $\Delta K_{\text {eff }}$ is the effective stress intensity range at the tip of the propagating fatigue crack and $\Delta K_{\text {eff }}<\Delta K$, the applied stress intensity range. It has been generally accepted that crack tip processes resulting from an overload reduce $\Delta K_{\text {eff }}$ and, therefore, retard the crack growth rate.

Both crack tip residual compressive stresses and crack closure can be related to the magnitude of the crack tip plastic zone. Interactions between the plastic zone of the propagating fatigue crack and the larger overload plastic zone have been postulated to control crack growth retardation [6-8]. Models have been developed $[9,10]$ which require the crack tip or its plastic zone to move beyond the overload plastic zone in order to resume the baseline crack growth rate. However, a complete understanding of fatigue crack retardation has not yet been realized. For example there is still uncertainty as to the exact contribution of plastic zone development to crack retardation. It has been noted [11,12] that there is a good correlation between the overload plastic zone size and the crack growth distance over which retardation occurs. However, evidence has also been presented which shows that the region of crack growth retardation extends over distances considerably larger than the overload plastic zone size $[13,14]$. The work reported here was conducted to provide additional insight into the relationship between overload plastic zone size and crack growth retardation. 


\section{EXPERIMENTAL PROCEDURE}

Single-edge-notch (SEN) specimens $76 \mathrm{~mm}$ ( $3 \mathrm{in}$.) wide and $127 \mathrm{~mm}(5 \mathrm{in}$.) long were machined from $3.18 \mathrm{~mm}(0.125 \mathrm{in}$.) thick stock of mill-annealed Inconel 600 . Details of the specimen design are given in Ref. [15]. Composition and mechanical properties of the Inconel 600 heat used in these experiments are given in Table 1. Standard metallographic techniques were used to prepare smooth and flat specimen surfaces to facilitate the measurement of crack length changes during fatigue.

Constant $\Delta K$ fatigue crack growth tests were performed on a closed-loop servo-hydraulic test machine. All baseline growth rate data was obtained for a $\Delta K$ of $32.9 \mathrm{MPa} \sqrt{\mathrm{m}}(30 \mathrm{ksi} \sqrt{\mathrm{in}}$ ) using a sinusoidal wave form at a frequency of $30 \mathrm{~Hz}$ and a load ratio, $R$, of 0.1 . Load shedding was used to keep $\Delta K$ within $2 \%$ of the desired value. All overloads were applied at a frequency of $0.1 \mathrm{~Hz}$. Crack length changes were measured with a travelling microscope capable of resolving a crack length change of $0.025 \mathrm{~mm}(0.001 \mathrm{in}$.). The stress intensity factor is determined from the expression [17] given in eqn (2).

$$
K=(P \sqrt{a} / B W)\left\{1.99-4.1(a / W)+18.7(a / W)^{2}-38.5(a / W)^{3}+53.85(a / W)^{4}\right\}
$$

where $P$ is the load applied to the sample $(\mathrm{N}) ; a$ is the crack length $(\mathrm{m}) ; B$ is the sample thickness $(\mathrm{m})$; and $W$ is the sample width $(\mathrm{m})$. When steady state crack growth was achieved under the baseline conditions, the test was interrupted and a single overload was applied. Crack growth behavior following overloads of $10,21,30,41$ and $50 \%$, where

$$
\% \text { overload }=\frac{K_{\text {overload }}-K_{\max }}{K_{\max }} \times 100
$$

were studied.

In the region affected by the overload, crack growth rates, $\mathrm{d} a / \mathrm{d} N$, were computed from $a$ vs $N$ data by the incremental polynomial method recommended in ASTM-E647.

\section{RESULTS AND DISCUSSION}

The magnitude of the retardation effect was determined in this study by measuring $a^{*}$, the increment in crack length, over which the crack growth rate is affected by the overload. The number of delay cycles, $N^{*}$, with overload was also observed.

As shown in Fig. 1, the constant $\Delta K$ baseline tests produced reasonably linear $a$ vs $N$ data. This allowed rather accurate determination of $N^{*}$ which was also used to quantify the magnitude of crack growth retardation. The construction used to obtain $a^{*}$ and $N^{*}$ is shown in Fig. 1 along with typical data showing the retardation effect for three different overloads. As expected the retardation effect increased with increasing overload magnitude. The variation of the affected crack length with overload for the data generated in this study is shown in Fig. 2. At low overload very little retardation is observed. However, at large overloads the affected crack length becomes substantial. Although not shown, a similar trend for the variation of delay cycles, $N^{*}$, and $a *$. From these data, one can determine how $a^{*}$ varied with the plastic zone sizes produced by the overloads. In past comparisons most correlations have been made between $a^{*}$ and either the plane stress or plane strain plastic zone sizes calculated from:

$$
r_{p}=\left(K_{0} / \sigma_{y}\right)^{2}
$$

\begin{tabular}{|c|c|c|c|c|c|c|c|c|c|}
\hline compesition & (wtz) & $74.0 \mathrm{Ni}$ & $15.2 \mathrm{Cr}$ & $9.2 \mathrm{Fe}$ & $0.40 \mathrm{Cu}$ & $0.24 A 1$ & $0.24 \mathrm{~T} i$ & $0.24 M 0$ & $0.03 \mathrm{C}$ \\
\hline \multirow[t]{2}{*}{ Properties } & grain & size: 30 & $\mathbf{m}$ & \multicolumn{3}{|c|}{ hardness $\left\langle R_{B}\right\rangle: 84$} & & & \\
\hline & \multicolumn{3}{|c|}{$\begin{array}{c}0.28 \text { offset yield } \\
\text { strength: } 296 \mathrm{MPa}\end{array}$} & \multicolumn{3}{|c|}{$\begin{array}{l}\text { tensile } \\
\text { strength: } 655 \mathrm{MPa}\end{array}$} & \multicolumn{2}{|c|}{$\begin{array}{l}\text { uniform } \\
\text { elongation (8): }\end{array}$} & 35 \\
\hline
\end{tabular}

Table 1. Composition and mechanical properties of Inconel 600 alloy used in this work[15] 


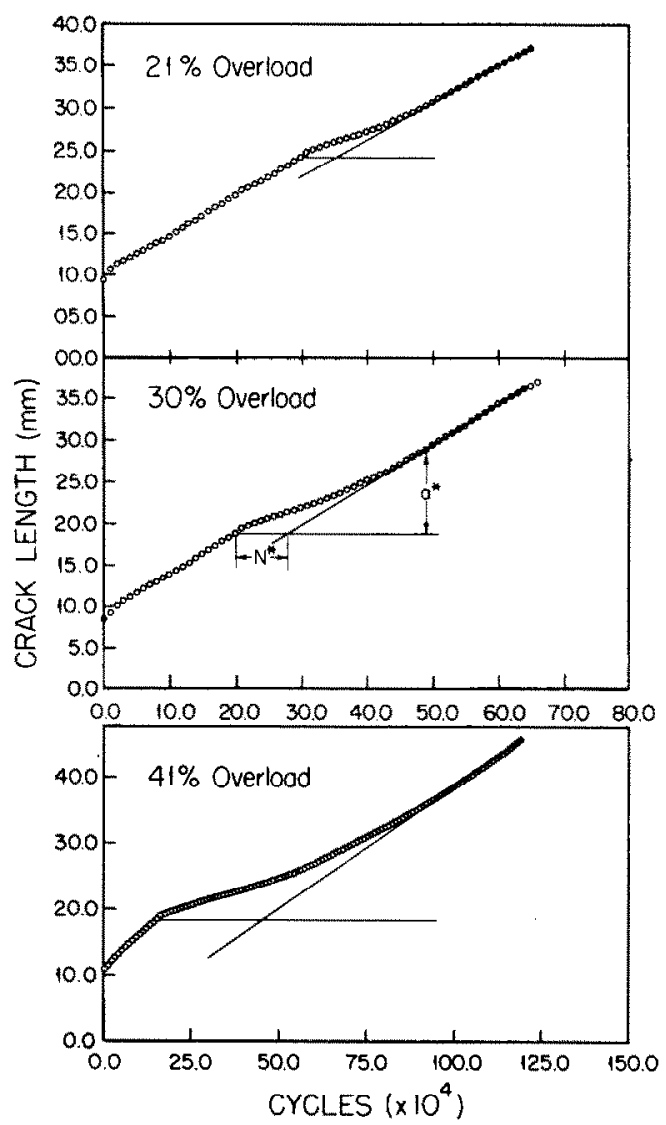

Fig. 1. Plots of $a$ vs $N$ showing the effect of a single overload cycle on crack growth behavior; (a) $21 \%$ overload, (b) $30 \%$ overload, (c) $41 \%$ overload.

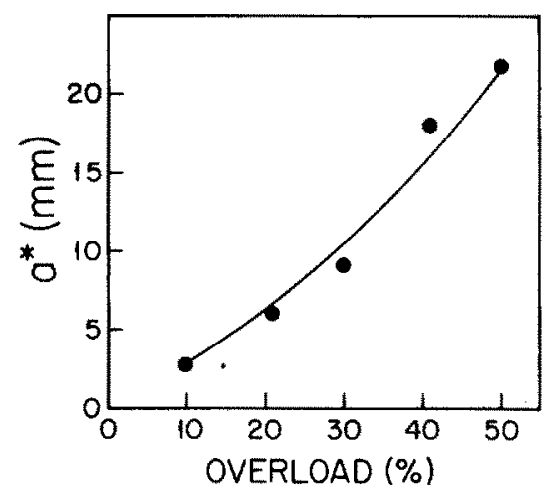

Fig. 2. Affected crack length, $a^{*}$, as a function of the overload magnitude.

where $r_{p}$ is the plastic zone diameter for an assumed circular plastic zone and $K_{0}$ and $\sigma_{y}$ are the overload stress intensity factor and yield stress respectively. The constant $\beta$ is often taken as $1 / \pi$ for plane stress and $1 / 3 \pi$ for plane strain. Experimental verification of the theoretical plastic zone size is seldom found[18], however. To overcome this difficulty we chose to determine $\beta$ from experimental measurement of the deformed region around the crack tip for a $41 \%$ overload and to use the experimentally determined constant to calculate plastic zone sizes for all overloads. The crack tip region showing the plastic deformation produced by a $41 \%$ overload is shown in Fig. 3 . From measurements of this deformed region $\beta$ was found to be 0.237 . It should be noted that the specimens used in this study were only $3.18 \mathrm{~mm}$ thick and plane stress conditions should prevail. The measured plastic zone sizes were approx. $25 \%$ smaller than the theoretical plane stress values. 


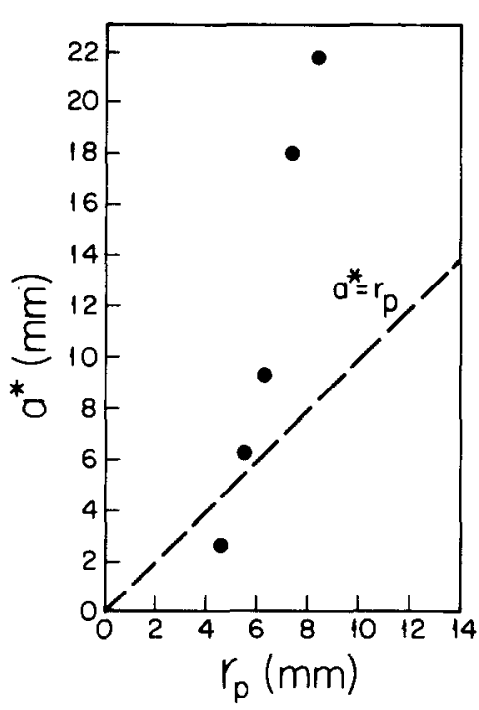

Fig. 4. Variation of affected crack length, $a^{*}$, with overload plastic zone size.

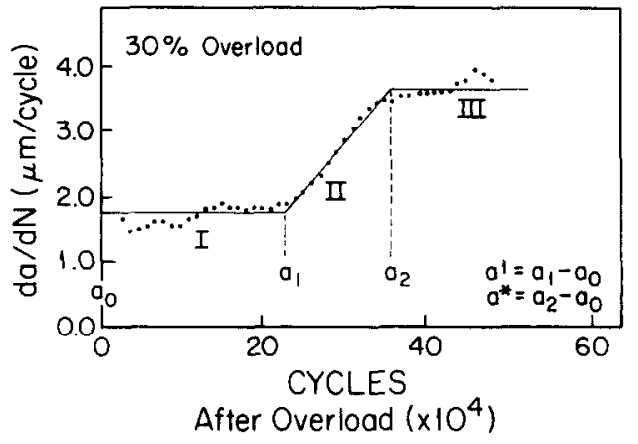

Fig. 5. Variation of $\mathrm{d} a / \mathrm{d} N$ with the number of cycles following an overload.

Figure 4 shows the variation of $a^{*}$ with the overload plastic zone size. At small overloads the affected crack length is on the order of the overload plastic zone size. At larger overloads, however, $a^{*}$ greatly exceeds the overload plastic zone size. The dashed line in Fig. 4 is the line for which $a^{*}=r_{p}$. It should be noted that the failure of the data in Fig. 4 to extrapolate to the origin results from the crack tip deformation associated with baseline crack propagation at $\Delta K=32.9 \mathrm{MPa} \sqrt{\mathrm{m}}$ ( $30 \mathrm{ksi} \sqrt{\text { in. }}$.) For the baseline conditions imposed, $K_{\max }=36.5 \mathrm{MPa} \sqrt{\mathrm{m}}(33.3 \mathrm{ksi} \sqrt{\mathrm{in}}$.), a plastic zone $3.7 \mathrm{~mm}$ wide should surround the fatigue crack. If the data in Fig. 4 were extrapolated to a value of $a^{*}=0$, the intercept on the abscissa would be roughly equivalent to this baseline fatigue plastic zone size.

The fatigue crack growth rate, $\mathrm{d} a / \mathrm{d} N$, following the overload gradually decreased from the pre-overload rate to a minimum value and remained at or near this minimum value for some time before gradually increasing to the pre-overload growth rate. Data showing this behavior for a $30 \%$ overload is presented in Fig. 5. It was observed that the growth rate immediately after the overload increased slightly and then began to decrease rapidly to a minimum value. Because of the seven point incremental polynomial used to reduce the $a$ vs $N$ data, the growth rate data immediately after overload were omitted. Neglecting the transients in crack growth rate that occur immediately following overload, the crack growth rate behavior can be divided into three regions in terms of crack length or cycles: Region I where minimum crack growth rate persists, Region II where a steady increase in crack growth rate occurs with increasing crack length and Region III where the crack growth rate returns to the preoverload value. Referring to Fig. 5 , if $a_{0}$ is defined as the crack length at the transition from Region I to Region II, then we can define

$$
a^{\prime}=a_{1}-a_{0}
$$

to be the crack length increment at minimum crack growth rate. Similarly, $a^{*}$ is defined as

$$
a^{*}=a_{2}-a_{0}
$$

and is consistent with the previous definition. From this data one can compute the effect of the overload on reducing subsequent crack growth rate. In Fig. 6 the ratio of minimum growth rate, $(\mathrm{d} a / \mathrm{d} N)_{\min }$, to the baseline crack growth rate $(\mathrm{d} a / \mathrm{d} N)_{\text {baseline }}$ is shown as a function of overload magnitude. As expected there is a strong dependence of overload magnitude on the minimum crack growth rate with small overloads producing only minor perturbations in growth rate.

Figure 7 shows a plot of $a^{\prime}$ vs the overload plastic zone size, $r_{p}$. Note again that the intercept on the abscissa agrees very well with the baseline plastic zone size. The distance, $a^{\prime}$, over which the crack propagates at the minimum growth rate is slightly larger than the measured plastic zone and roughly equivalent to the theoretical plane stress plastic zone size. It appears that the crack 


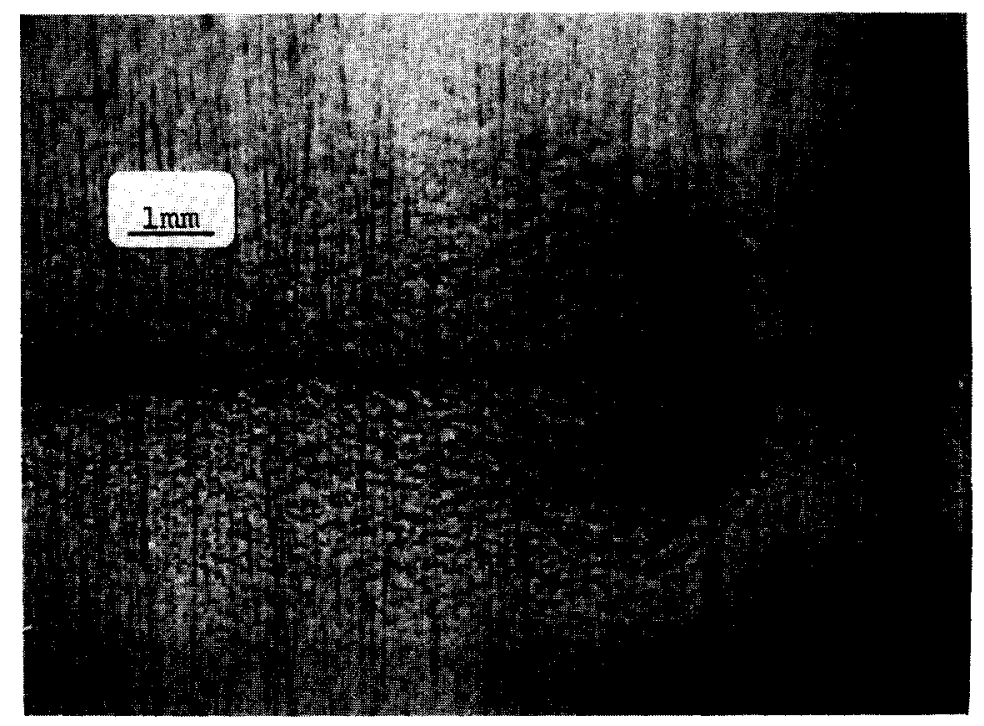

Fig. 3. Photograph of the overload region for a $41 \%$ overload.

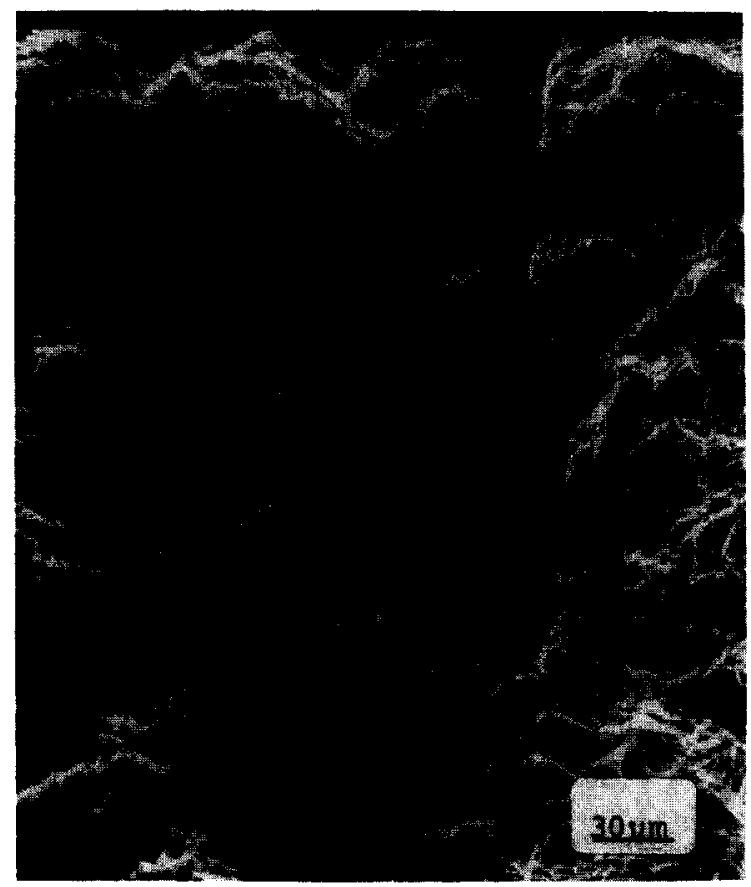

Fig. 8. Fractograph of the overload region for a $41 \%$ overload. 


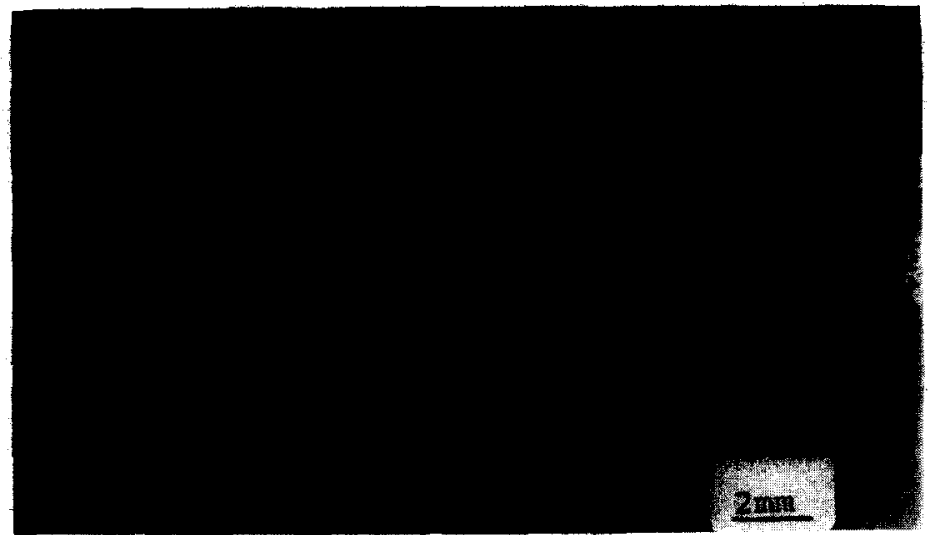

Fig. 9. Macrophotograph of the fracture surface of the sample subjected to a $41 \%$ overload. 


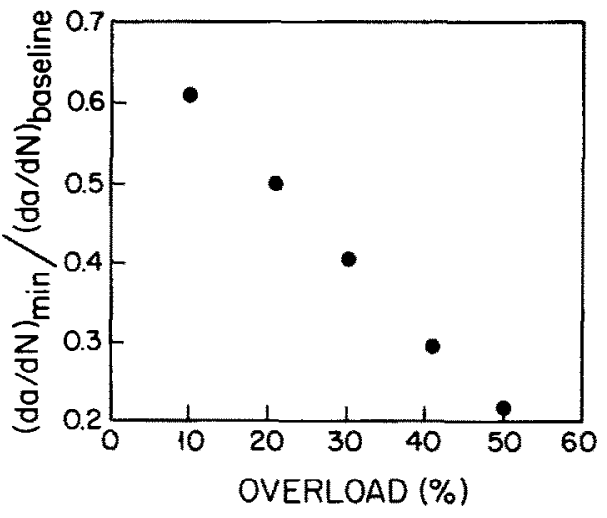

Fig. 6. Ratio of the minimum crack growth rate following the overload to the baseline crack growth rate as a function of overload magnitude.

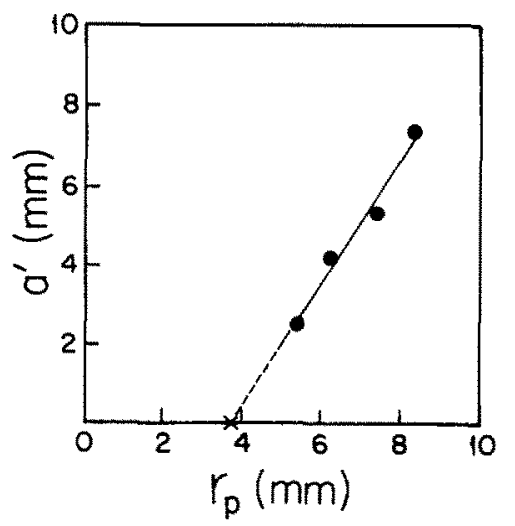

Fig. 7. Relationship between the crack length increment at minimum crack growth rate, $a^{\prime}$, and the overload plastic zone size.

must grow beyond the overload plastic zone boundary before the growth rate begins its return to the baseline growth rate.

Figure 8 shows the fatigue crack surface in the region of the $41 \%$ overload. Crack growth is from right to left in this figure and a sharp delineation between the pre-overload and post-overload region can easily be seen. Crack growth at baseline conditions results in predominately faceted crack surfaces typical of crack growth in nickel-base materials. No striation formation is observed. In the overload region, however, extensive evidence of crack surface contact is seen. It appears that the contact points in this region have produced wear patterns similar to what would be expected under fretting conditions. In the region of the overload the evidence of contact extends across the entire specimen surface and gradually disappears as the distance beyond the overload point increases. It becomes obvious that extensive crack closure resulted from the overload.

Analysis of these data indicate that (1) both the minimum crack growth rate and significant retardation occur within the plane stress overload plastic zone and (2) the effect of the overload extends well beyond the overload plastic zone. These observations are in agreement with the recent work of Gan and Weertman $[13,19]$ who found that the crack closure stress was affected by a single cycle overload even after the crack had advanced well beyond the overload plastic zone. They also showed that the crack growth rate returned to the pre-overload value only after the crack had advanced a sufficient distance for the crack closure stress to return to its pre-overload value. Within the overload plastic zone the crack closure stress measured by Gan and Weertman[19] was essentially constant. This offers a possible explanation for our observations of a rather constant crack growth rate as the crack traverses the overload plastic zone.

It is resonable to assume that for $3.18 \mathrm{~mm}$ thick Inconel 600 specimens subjected to rather high loading the stress state was essentially plane stress. The increased amount of deformation across the plastic zone serves as a significant wedge of excess material to raise the closure stress and thereby decrease $\Delta K_{\text {eff }}$. Of significance here is that physical crack closure, that is, the apparent contact between crack faces, only occurs in the region of the overload plastic zone. Figure 9 is a macrophotograph of the fracture surface for the sample subjected to the $41 \%$ overload. As in Fig. 8 an abrupt transition occurs in crack surface appearance at the location of the overload application. The darkening of the fracture surface in the post-overload region results from the fretting action between the crack faces as a result of crack closure. An appoximation of the region over which crack closure occurred can be made by measuring the distance over which this fretting discoloration is visible. For the sample shown in Fig. 9, this region extends between 4 and $5 \mathrm{~mm}$ from the overload location. This is approximately half the size of the plastic zone.

It is apparent that two types of closure phenomena are contributing to the crack growth retardation in sheet specimens of Inconel 600 . Within the overload plastic zone contact between the crack faces occurs during a portion of the fatigue cycle and near-crack-tip contact results from the excessive deformation produced during the overload cycle. After the crack has grown beyond the overload plastic zone $\Delta K_{\text {eff }}$ is still smaller than the applied $\Delta K$ because the plastically deformed overload region acts as a wedge to keep the crack faces open. Only when the crack has advanced 
sufficiently far, so the increase in specimen compliance allows the crack tip region to experience the full applied stress range, will crack growth return to pre-overload behavior. This implies, as noted by Gan and Weertman [13] that crack closure load measurements must be made throughout the region of crack growth retardation if the modified Paris Law is to be successfully applied.

\section{CONCLUSIONS}

(1) Fatigue crack growth retardation in Inconel 600 is observed for single cycle overloads.

(2) The affected crack length, $a^{*}$, is considerably larger although related to, the overload plastic zone size, $r_{p}$.

(3) Within the overload plastic zone crack propagation is influenced by physical contact between the crack faces leading to a minimum crack propagation rate.

(4) A crack wedging effect resulting from the plastic deformation in the overload region is responsible for continued crack growth retardation as the crack advances well beyond the overload plastic zone.

[1] W. Elber, Engng Fracture Mech. 1, 37 (1970).

[2] W. Elber, The significance of crack closure. ASTM STP 486, 230 (1971).

[3] H. F. Hardrath, Fffects of changing stress amplitude on the rate of fatigue crack propagation in two aluminum alloys. NASA-TN-0-960, Washington D.C. (1961).

[4] P. J. Barnard et al., Mechanisms of overload retardation during fatigue crack propagation. In Fatigue Crack Growth Under Spectrum Loads, ASTM STP 595, 78-97 (1971).

[5] J. E. Srawley et al., NASA-TMX-52904, Lewis Research Center, Cleveland, Ohio (1970).

[6] E. F. J. von Euw, R. W. Hertzberg and R. Roberts, Delay effect in fatigue crack propagation. ASTM STP 513, 230-259 (1972).

[7] W. J. Mills and R. W. Hertzberg, The effect of sheet thickness on fatigue crack ratardation in 2024-T3 aluminum alloys. Engng Fracture Mech. 7, 705-711 (1975).

[8] T. T. Shih and R. P. Wei, Effect of specimen thickness on delay in fatigue crack growth. JTEVA 3, 46-47 (1975).

[9] O. E. Wheeler, J. Basic Engng, ASME, 181-186 (1972).

[10] J. Willenburg, R. M. Engle and H. A. Wood, A crack growth retardation model using and effective stress concept. AFFOL-TM-71-1-FBR, Air Force Flight Dynamics Laboratory (1971).

[11] G. J. Petrak, Strength level effects on fatigue crack growth and retardation. Engng Fracture Mech. 6, 725-735 (1974).

[12] S. Matsuoka and K. Tanaka, Delayed retardation phenomena of fatigue crack growth resulting from a single application of overload. Engng Fracture Mech. 10, 515-525 (1978).

[13] D. Gan and J. Weertman, Fatigue crack closure after overload. Engng Fracture Mech. 18, $155-160$ (1983).

[14] V. W. Trebules, Jr., R. Roberts and R. W. Hertzberg, Effect of multiple overloads on fatigue crack propagation in 2024-T3 alumininum alloy. ASTM STP 536, 115 (1973).

[15] G. S. Was, H. H. Tischner, R. M. Latanision and R. M. Pelloux, Fatigue crack growth behavior of Inconel 600 at cathodic potentials. Metall. Trans. A 12A, 1409-1418 (1981).

[16] G. S. Was, ScD Thesis, Massachusetts Institute of Science and Technology, Cambridge, Mass. (June 1980).

[17] D. Broek, Elementary Engineering Fracture Mechanics. Sythoff and Noodhoff, The Netherlands (1978).

[18] D. L. Davidson and J. L ankford, Fatigue crack tip plasticity resulting from load interaction in an aluminum alloy. Fatigue Engng Mater. Structures 1, 439-446 (1979).

[19] D. Gan and J. Weertman, Crack closure and crack propagation in 7050 aluminium. Engng Fracture Mech. 15, 81 (1981). 